Article

\title{
Development of a New Clean Development Mechanism Methodology for the Quantification of Greenhouse Gas in Calcium Sulfoaluminate Cement
}

\author{
Eun-don Jeon $\mathbb{D}^{\mathbb{D}}$, Kyu-uk Lee and Chung-kook Lee * \\ Korea Research Institute on Climate Change, Chuncheon-si, Gangwon-do 24239, Korea; \\ Jeoned@Kric.re.kr (E.-d.J.); Kyuuklee@Kric.re.kr (K.-u.L.)
}

Received: 31 January 2019; Accepted: 5 March 2019; Published: 11 March 2019

\begin{abstract}
The purpose of this research was to probe beyond the scope of the "National Strategy Project on Carbon Mineralization" to develop a "United Nations Framework Convention on Climate Change, Clean Development Mechanism" (UNFCCC CDM) methodology that enables reduction of greenhouse gas (GHG) by "green cement" under the calcium sulfoaluminate (CSA) cement technologies. The findings will be utilized as the foundations and developed into the UNFCCC CDM project. There were two existing methodologies related to cement, but neither was applicable for CSA cement. The existing methodologies are applicable only when there is one clinker, but CSA cement utilizes more than one clinker. Through this research, we developed methodologies to use waste-based material for avoiding emission leakage and utilized more than one clinker to calculate GHG emissions and reduction. For this purpose, we utilized the CSA cement methodology for calculating GHG reduction compared to Portland cement and found that CSA cement allowed for a reduction of 0.281 $\mathrm{tCO}_{2}$-eq/ton above the reduction enabled by Portland cement. We are presently preparing to register the CSA cement methodology for UNFCCC CDM methodology approval. With the technology transfer and support for this CSA cement technology and methodology, developing countries will be able to achieve their national GHG reduction targets and gain carbon credits. Thus, CSA cement technology could serve as an important tool to deal with GHG emissions and climate change.
\end{abstract}

Keywords: green cement; climate change; $\mathrm{CO}_{2}$; clean development mechanism; $\mathrm{CDM}$ methodology; carbon credit; emission trading scheme

\section{Introduction}

Under the Paris Agreement, the international community has set national greenhouse gas reduction targets that are to be met by 2030. Korea has announced that it will set its national greenhouse gas reduction target at $37 \%$ against the 2030 emission estimate (Business as Usual) through the INDC (intended nationally determined contribution). Through the 2030 National Greenhouse Gas Reduction Roadmap, $37 \%$ is divided into $32.5 \%$ domestic reductions and $4.5 \%$ overseas (international) reductions. Within the INDC, only the total reduction targets are specified and the targets for overseas reductions are not specified; however, additional preparations are necessary to achieve the reduction targets. As of 2016, Korea's total industrial greenhouse gas emissions amounted to 51,456 million $\mathrm{tCO}_{2}$-eq and the cement sector accounted for $49.6 \%$, at 25,543 million $\mathrm{tCO}_{2}$-eq [1]. Thus, in order to reduce greenhouse gases in the industrial sector, a lot of efforts are needed in the cement sector.

Korean cement companies are designed and managed by the ETS (Emission Trading Scheme) and TMS (Target Management System) considering the large amount of greenhouse gas emissions. Companies have studied a variety of ways to reduce greenhouse gases. Among them, some cement companies have developed CSA (calcium sulfoaluminate) cement with a lower rate of greenhouse 
gas emissions compared to conventional OPC (ordinary Portland cement) as a means to reduce greenhouse gas emissions. It is now necessary to develop a new methodology for the United Nations Framework Convention on Climate Change, Clean Development Mechanism (UNFCCC CDM) that meets CSA cement technology at an international level. The methodology will serve as a means for CSA cement developers to quantify greenhouse gas reductions. As of now, there is a "cement production methodology," which is a registered methodology in the CDM, but this cannot be applied to CSA cement technology. Therefore, this study aimed to develop a new methodology for CDM that can quantify greenhouse gas reductions of mixed cement products using two or more clinkers with CSA cement technology.

\section{Theoretical Background}

The Clean Development Mechanism (CDM) is a greenhouse gas reduction program under the Tokyo Protocol. The reduced amount of greenhouse gas in non-annex countries (countries that have ratified or accepted UNFCCC but are not obligated to reduce greenhouse gas emissions) can be verified through the third-party verification agency and utilized as an accomplished goal or a trading type of carbon credit. In order to receive the verification of carbon credit, a project should proceed with the CDM methodology certified by UNFCCC. The CDM methodology means an applicable standards of additionality, baseline, and monitoring methods for the registration of the CDM project and the verification of a greenhouse reduction amount regarding the greenhouse reduction project.

A quantitative method for the emission amount of greenhouse gas by cement has been internationally presented in " $\mathrm{CO}_{2}$ Accounting and Reporting Standard for the Cement Industry" [2] issued by The World Business Council for Sustainable Development (WBCSD) and the "2006 IPCC Guidelines for National Greenhouse Gas Inventories" [3]. In Korea, its method has been utilized in TMS and ETS with an emission amount of greenhouse gas computed using "instruction for the goal management and operation of greenhouse gas energy" [4]. Previous studies have the same theoretical computational equation for the emission amount of greenhouse gas and the differences in the boundary of operation, the kinds of greenhouse gas to report, and the consideration of indirect emission by the purpose (e.g., a report for the emission amount of greenhouse gas by a company, an establishment of a national inventory for greenhouse gas, etc.).

In the case of the CDM methodology, for the purpose of a computation of the reduced amount of greenhouse gas, only the emission amount of greenhouse gas by the facility or process shall be computed with the application of the reduction technology since the greenhouse gas differs from the computation method of previous studies. The rest shall be excluded for simplification. Therefore, life cycle assessment (LCA) is a powerful tool for computing the amount of greenhouse gas emissions, which has not been considered as it is different from the concept of CDM methodology in the present study.

The CDM project should be promoted with the CDM methodology certified by UNFCCC. There are two cases of methodologies for the cement production registered in the UNFCCC, but to apply them to the manufacturing process of CSA cement, a new methodology should be developed. The contents of the new methodology must include an equation to compute the reduction amount of greenhouse gas in CSA cement accurately. An applicability must be set for completed and consistent computation.

\section{Methods}

In this research, UNFCCC CDM methodologies related to cement were analyzed, and the applicable conditions for CSA cement production were determined. However, there were no methodologies suitable for CSA cement, and hence we developed new methodologies for quantification of GHG reduction by means of using CSA cement. For developing methodologies, we analyzed standard process for two methodologies, their applicability, and method of GHG emissions calculation for the validation of the new methodology. We developed new CSA cement methodologies and are 
presently preparing to register at UNFCCC CDM for the approval process. Also, we have provided limited information on this research for privacy reasons. In summary, we provide the estimated GHG reduction achieved by utilizing the new CSA cement methodology.

\section{Results}

\subsection{Demand for the New CDM Methodology}

To be issued carbon credits from the UNFCCC CDM, it is mandatory to register the CDM project via the approved methodology from the UNFCCC. In UNFCCC CDM, there are 216 registered methodologies and 2 related cement methodologies (Table 1).

Table 1. Methodologies on UNFCC CDM (Cement Production).

\begin{tabular}{cc}
\hline Methodology & Title \\
\hline ACM0005 & Increasing the blend in cement production \\
ACM0015 & Emission reductions from raw material switch in clinker production \\
\hline
\end{tabular}

In the ACM (approved consolidated methodology) 0005 [5] methodology, GHG reduction is mainly achieved through increasing the "ratio of mixed material" in the process of cement mixing/grinding to reduce the clinker production. This enables: (1) reduction of $\mathrm{CO}_{2}$ in the process emission in the kiln process (decarboxylation of limestone), and (2) reduction of fossil fuel usage during the kiln process.

The ACM0015 [6] methodology's main principle is to replace limestone with non-carbonate material so as to reduce the usage of limestone and fossil fuel in the kiln process and $\mathrm{CO}_{2}$ emissions in the process.

In CDM, 17 projects applying these two methodologies were approved by the UNFCCC. The total GHG reduction per year for these projects was approximately 2,559,000 $\mathrm{tCO}_{2}$-eq.

In this research, CSA cement was used for: (1) replacing the limestone in the "raw material input" for reduction of $\mathrm{CO}_{2}$ emission and fossil fuel usage in the kiln process, and (2) adding mixed material for reducing usage of a clinker that in turn brought down the $\mathrm{CO}_{2}$ emission in the cement mixing/grinding process (Figure 1). Therefore, for achieving those conditions, we needed to compound those two methodologies, viz. ACM0005 and ACM0015.

\begin{tabular}{|c|c|c|c|c|c|c|c|}
\hline Reference & $\begin{array}{l}\text { Raw Material Mix } \\
\text { (Limestone, etc.) }\end{array}$ & $\Rightarrow$ & $\begin{array}{l}\text { Calcination } \\
\left(1450^{\circ} \mathrm{C}\right)\end{array}$ & $\Rightarrow$ & $\begin{array}{l}\text { Mixing and } \\
\text { Grinding } \\
\text { (Gypsum, etc.) }\end{array}$ & $\Rightarrow$ & $\begin{array}{l}\text { Portland } \\
\text { Cement }\end{array}$ \\
\hline This Study & $\begin{array}{l}\text { Raw Material Mix } \\
\text { (Limestone, } \mathrm{Al} \mathrm{O}_{3} \text {, etc) }\end{array}$ & $\Rightarrow$ & $\begin{array}{l}\text { Calcination } \\
\left(1250^{\circ} \mathrm{C}\right)\end{array}$ & $\Rightarrow$ & $\begin{array}{c}\text { Mixing and } \\
\text { Grinding } \\
\text { (Gypsum, OPC, etc.) }\end{array}$ & $\Rightarrow$ & $\begin{array}{c}\text { CSA } \\
\text { Cement }\end{array}$ \\
\hline $\begin{array}{l}\text { Reduction } \\
\text { GHG }\end{array}$ & \multicolumn{7}{|c|}{ - Fixed Combustion: $\mathrm{CO}_{2}, \mathrm{CH}_{4}, \mathrm{~N}_{2} \mathrm{O}$ o Process Emissions : $\mathrm{CO}_{2}$} \\
\hline $\begin{array}{c}\text { Reduction } \\
\text { Principle }\end{array}$ & \multicolumn{7}{|c|}{$\begin{array}{l}\text { 1) Decrease in carbon dioxide } \mathrm{CO}_{2} \text { process emissions from calcination process } \\
\text { due to decrease of limestone usage by alternative raw materials }\left(\mathrm{Al}_{2} \mathrm{O}_{3} \text {, etc.) in }\right. \\
\text { clinker production process } \\
\text { 2) Reduction of fossil fuel consumption due to lowering of calcination } \\
\text { temperature due to input of alternative raw materials ( } \mathrm{Al}_{2} \mathrm{O}_{3} \text {, etc.) } \\
\text { 3) Decreased production of clinker using mixed materials (gypsum, OPC, } \\
\text { etc.) in cement mixing and grinding process }\end{array}$} \\
\hline
\end{tabular}

Figure 1. GHG reduction principle in CSA cement. 
Also, ACM0005 and ACM0015 only allow utilization of one clinker for calculations of GHG reduction. For this reason, these two methodologies cannot be applied to CSA cement that has to mix OPC clinkers (more than one) for maintaining the quality.

\subsection{Development of New CDM Methodology}

As previously mentioned, the registered CDM methodologies were not applicable for utilization in the CSA cement process. For obtaining approval for the GHG reduction effect of CSA cement, it is necessary to apply the registered CDM methodologies to the CSA cement methodology. Within the two methodologies, GHG reduction happens during the "mixing and grinding process" of ACM0005, whereas it is the "raw material mix process" that enables GHG reduction under ACM0015. However, for CSA cements, GHG reduction happens during both of the processes. These were the reasons why it was necessary to develop a new methodology for the CSA cement process (Figure 2).

\begin{tabular}{|c|c|c|}
\hline ACM 0005 & ACM 0015 & Development Methodology \\
\hline $\begin{array}{l}\text { Increasing the blend in } \\
\text { cement production }\end{array}$ & $\begin{array}{c}\text { Emission reductions from } \\
\text { raw material } \\
\text { switch in clinker production }\end{array}$ & $\begin{array}{c}\text { Reduction of GHG emission } \\
\text { from mixed cement products } \\
\text { using CSA clinker }\end{array}$ \\
\hline PROCESS & PROCESS & PROCESS \\
\hline Raw Material Mix & Raw Material Mix & Raw Material Mix \\
\hline$\downarrow$ & $\downarrow$ & $\downarrow$ \\
\hline $\begin{array}{l}\text { Calcination } \\
\left(1450^{\circ} \mathrm{C}\right)\end{array}$ & $\begin{array}{l}\text { Calcination } \\
\left(1450^{\circ} \mathrm{C}\right)\end{array}$ & $\begin{array}{l}\text { Calcination } \\
\left(1250^{\circ} \mathrm{C}\right)\end{array}$ \\
\hline$\downarrow$ & $\downarrow$ & $\downarrow$ \\
\hline Mixing and Grinding & Mixing and Grinding & Mixing and Grinding \\
\hline$\Downarrow$ & $\Downarrow$ & $\Downarrow$ \\
\hline Cement & Cement & Cement \\
\hline $\begin{array}{l}\square \text { Mixing and Grinding } \\
\cdot \text { Decreased clinker } \\
\text { production }\end{array}$ & $\begin{array}{l}\square \text { Raw Material Mix } \\
\cdot \text { Reduce calcination } \\
\text { emissions } \\
\square \text { Mixing and Grinding } \\
\cdot \text { Decreased clinker } \\
\text { production }\end{array}$ & $\begin{array}{l}\text { Raw Material Mix } \\
\cdot \text { Reduce calcination } \\
\text { emissions } \\
\cdot \text { Reduce fossil fuel use } \\
\square \text { Mixing and Grinding } \\
\cdot \text { Decreased clinker } \\
\text { production }\end{array}$ \\
\hline
\end{tabular}

Figure 2. GHG reduction principle in CSA cement.

\subsubsection{Applicability}

Applicability of the new CDM methodology is presented in Table 2.

Related to the applicability of the CSA cement export parts, GHG reduction here happens during the production phase of the technology, and therefore the export part is excluded from the applicability conditions. In addition, GHG reduction for CSA cement tech mainly happens during the "clinker process" and thus can be categorized as a reduction in "process emissions," since we created the block condition that does not fit in the new methodologies. Also, we presented methodologies to ensure quality and compare quality of the produced cement during the baseline and project scenario with support from the applicable third-party certification institutions.

Especially, we enabled utilization of only waste materials, excluding mineral materials, as alternative material for the CSA cement production process. The reason for excluding mineral 
materials was to prevent emission leakage during the mining and transport process and thereby curb the total emission from the CSA cement production process.

Table 2. Applicability of the development methodology.

\section{Applicability}

1. This methodology can be applied to cement mixing processes sold in the target country. However, the emission reductions achieved during the process exclude reductions in greenhouse gas emissions after cement shipment.

2. All clinkers used in the project should be produced at the cement plant located within the business boundary, and the whole cement production process must be performed at the cement plant located within the project boundary.

3. There must be a component and quality standard for each type of cement certified by a country or a third-party certification body. It should be possible to compare the quality of cement produced in this project with the quality of cement produced in the baseline scenario.

4. Baseline clinker production raw materials should include $\mathrm{CaCO}_{3}$ and $/$ or $\mathrm{MgCO}_{3}$, and the project should use raw materials (such as fly ash) that can be partially or completely replaced.

5. The additional effect of clinker production using alternative raw materials may extend over the lifetime, but the objective of the project should not be to increase the capacity and extend the life of the equipment.

6. The quality of the produced cement must meet the cement quality standards of the country concerned.

7. It should be demonstrated that alternative raw materials and additive materials did not result in increased emissions in other areas.

8. Alternative raw materials related to the production of CSA clinkers should be waste-based and not mineral-based.

\subsubsection{GHG Emission Calculation Method}

In the methodology, the GHG emission takes place during the clinker unit's and cement unit's development process. The project boundary is a cement production factory, facility factory (if there is one), or electricity grid. Also, indirect emission is equivalent to the loss of a power plant or electricity grid when purchasing the power. The alternative material and additives' transport emission is included apart from these, but the transport emission for the raw material for producing the clinker is excluded as a conservative simplification. The GHG emissions for the CSA cement process could be divided into: (1) kiln emissions, (2) fossil fuel and power use for clinker production, and (3) power used for mixed grinding to prepare alternative raw materials and additives.

During the production of CSA cement clinker, OPC is added for equalizing the quality, but while utilizing the registered methodologies there are no ways to apply the CSA cement clinker (Equation (1)). Given this constraint, we developed a method for utilizing more than one clinker for emission calculations (Equation (2)):

$$
\mathrm{PE}_{\text {clinker, } \mathrm{y}}=\mathrm{PE}_{\text {calcin, } \mathrm{y}}+\mathrm{PE}_{\text {fossil fuel, } \mathrm{y}}+\mathrm{PE}_{\text {ele, grid, } \mathrm{CLNK}, \mathrm{y}}+\mathrm{PE}_{\mathrm{ele}, \mathrm{sg}, \mathrm{CLNK}, \mathrm{y}}
$$

where:

$\mathrm{PE}_{\text {clinker, } \mathrm{y}}=\mathrm{CO}_{2}$ emissions per ton of clinker in the project activity plant in year " $\mathrm{y}$ " ( $\mathrm{t} \mathrm{CO}_{2} / \mathrm{t}$ clinker $)$

$\mathrm{PE}_{\text {calcin, } \mathrm{y}}=$ Emissions per ton of clinker due to calcination of calcium carbonate and magnesium carbonate in year " $y$ " ( $\mathrm{t} \mathrm{CO}_{2} / \mathrm{t}$ clinker $)$

$\mathrm{PE}_{\text {fossil fuel, } \mathrm{y}}=$ Emissions per ton of clinker due to combustion of fossil fuels for clinker production in year "y" ( $\mathrm{t} \mathrm{CO} 2 / \mathrm{t}$ clinker)

$\mathrm{PE}_{\text {ele, grid, } \mathrm{CLNK}, \mathrm{y}}=\mathrm{Grid}$ electricity emissions for clinker production per ton of clinker in year " $\mathrm{y}$ " ( $\mathrm{t} \mathrm{CO}$ / t clinker)

$\mathrm{PE}_{\text {ele, }} \mathrm{sg}$, CLNK, $\mathrm{y}=$ Emissions from self-generated electricity per ton of clinker production in year " $\mathrm{y}$ " (t $\mathrm{CO}_{2} / \mathrm{t}$ clinker) 


$$
\mathrm{PE}_{\text {clinker }, \mathrm{y}}=\sum\left\{\left(\mathrm{PE}_{\text {calcin, i, } \mathrm{y}}+\mathrm{PE}_{\text {fossil fuel, i, } \mathrm{y}}+\mathrm{PE}_{\text {ele, grid, } C L N K, \mathrm{i}, \mathrm{y}}+\mathrm{PE}_{\text {ele, sg, CLNK, i, y }}\right) \times \mathrm{P}_{\mathrm{CLNK}, \mathrm{i}, \mathrm{y}}\right\}
$$

where:

$\mathrm{PE}_{\text {clinker, } \mathrm{y}}=\mathrm{CO}_{2}$ emissions per ton of clinker in the project activity plant in year " $\mathrm{y}^{\text {" }}\left(\mathrm{t} \mathrm{CO}_{2} / \mathrm{t}\right.$ clinker) $\mathrm{PE}_{\text {calcin, } \mathrm{i}, \mathrm{y}}=$ Emissions per ton of clinker i due to calcinations of calcium carbonate and magnesium carbonate in year " $\mathrm{y}$ " ( $\mathrm{t} \mathrm{CO} / \mathrm{t}$ clinker)

$\mathrm{PE}_{\mathrm{fossil}}$ fuel, $\mathrm{i}, \mathrm{y}=$ Emissions per ton of clinker i due to combustion of fossil fuels for clinker production in year " $\mathrm{y}$ " ( $\mathrm{t} \mathrm{CO} 2 / \mathrm{t}$ clinker)

$\mathrm{PE}_{\mathrm{ele}}$, grid, $\mathrm{CLNK}, \mathrm{i}, \mathrm{y}=$ Grid electricity emissions for clinker i production per ton of clinker in year " $\mathrm{y}$ " ( $\mathrm{CO}_{2} / \mathrm{t}$ clinker)

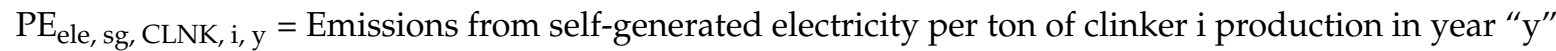
(t $\mathrm{CO}_{2} / \mathrm{t}$ clinker)

$\mathrm{P}_{\mathrm{CLNK}, \mathrm{i}, \mathrm{y}}=$ Percentage of clinker $\mathrm{i}$ in year " $\mathrm{y}$ " ( $\mathrm{t}$ clinker $/ \mathrm{t}$ clinker)

\subsection{Calculation of GHG Reduction}

We utilized the newly developed methodologies for calculating reduction in GHG for CSA cement. The calculated data was from Korea H Cement Company's "Production Basic Unit of Portland Cement" and "Projection Basic Unit of CSA Cement (Experimental Value)." The applied data is on Table 3. The amount of electricity used for clinker production, cement grinding, raw material, and additive preparation was assumed to be the same.

Table 3. Data for calculating GHG reductions.

\begin{tabular}{lccc}
\hline \multicolumn{1}{c}{ List } & Baseline (OPC) & Project (CSA) & Unit \\
\hline Amount of fossil fuel used for clinker production & 900 & 641 & Kcal/kg-clinker \\
\hline Electricity used in clinker production & 28.11 & 28.11 & KWh \\
\hline Free CaO Content & 0.004485 & 0.004848 & $\%$ \\
\hline CaO content of clinker produced & 0.623 & 0.44 & $\%$ \\
\hline Free MgO Content & 0.000142 & 0.000251 & $\%$ \\
\hline MgO content of clinker produced & 0.0308 & 0.0182 & $\%$ \\
\hline Amount of electricity used for cement grinding & 43.41 & 43.41 & KWh \\
\hline $\begin{array}{l}\text { Amount of electricity used to prepare raw materials } \\
\text { and additives }\end{array}$ & 25.43 & 25.43 & $\mathrm{KWh}$ \\
\hline Clinker mixing ratio of cement & 0.889 & 0.8 & $\%$ \\
\hline Additive mixing ratio of cement & 0.111 & 0.2 & $\%$ \\
\hline
\end{tabular}

Given these assumptions, the GHG reductions were calculated as shown in Table 4. The CSA cement production process achieved a reduction of $0.281 \mathrm{tCO}_{2}$-eq/ton above the reduction realized for Portland cement, which was the baseline. As determined during the research, the GHG reduction point was the "kiln process," where it was possible to curb the process emissions by reducing the fossil fuel usage and also by changing the ratio of the clinker content. In the latter, GHG reductions were calculated per ton of cement.

As for the "National Strategy Project of Carbon Mineralization," which is the fundamental $\mathrm{R} \& \mathrm{D}$ (research and development) for this research, the third phase plan is to produce 30,000 ton/year of CSA cement and thereby realize $8430 \mathrm{tCO}_{2}$-eq/year of GHG reduction. The resulting data of GHG reduction is based on the experimental values. If the CSA cement is produced by the generally considered method, the GHG reduction could be less than the values presented here. 
Table 4. GHG reduction calculation results.

\begin{tabular}{lccc}
\hline \multicolumn{1}{c}{ List } & Baseline (OPC) & Project (CSA) & Unit \\
\hline GHG Emissions in the Clinker & 0.876 & 0.621 & $\mathrm{tCO}_{2} / \mathrm{tClinker}$ \\
GHG Emissions from Calcination & 0.519 & 0.361 & $\mathrm{tCO}_{2} / \mathrm{tClinker}$ \\
GHG Emissions from Fossil Fuel Use & 0.342 & 0.243 & $\mathrm{tCO}_{2} / \mathrm{tClinker}$ \\
GHG Emissions from Electricity Use & 0.015 & 0.016 & $\mathrm{tCO}_{2} / \mathrm{tClinker}$ \\
GHG Emissions from Cement & 0.032 & 0.032 & $\mathrm{tCO}_{2} / \mathrm{tCement}$ \\
Grinding and Mixture Preparation & 0.810 & 0.529 & $\mathrm{tCO}_{2} / \mathrm{tCement}$ \\
Total GHG Emissions Unit & & $\mathbf{0 . 2 8 1}$ & $\mathrm{tCO}_{2} / \mathrm{tCement}$ \\
\hline GHG Reduction & & &
\end{tabular}

\section{Conclusions}

In this research, we attempted to develop a method for quantification of the reduction in GHG using a CSA cement process and developed CDM methodologies to register the CSA cement process as a CDM project in the UNFCCC. There are some registered methodologies related to cements, but those methodologies do not satisfy the conditions of CSA cement. Hence, we developed a new methodology for CSA cement. The new methodology describes how to calculate GHG reduction during the CSA cement process when more than one type of clinker is utilized. Using these calculations, it was found that the GHG reduction was $0.2851 \mathrm{tCO}_{2}$-eq/ton while producing 1 ton of CSA cement.

We believe that these new methodologies, once registered, will potentially have an impact on the following situations.

- Impact on developing countries cement technologies transfer and support for industrial parts.

- GHG reduction when utilizing and producing cement and thereby the chance for creating carbon credits (emissions).

- Will allow countries to choose material and technologies that enable reduction of GHG in their industrial sectors for their development.

This CSA cement technology could be utilized in developing countries' infrastructure construction sectors and will also realize a greater reduction in GHG compared to general cement. In addition, development of this new CDM methodology contains the possibility of allowing CDM principles after POST2020 under the Paris Agreement. For this, there has been opportunity for developing countries to consider the technologies under CDM. We also developed a type of Greenfield project for developing countries to develop their own CSA cement and achieve their GHG reduction targets.

Author Contributions: Conceptualization, E.-d.J.; Investigation, E.-d.J.; Supervision, C.-k.L.; Writing-Original draft, E.-d.J.; Writing-Review and editing, E.-d.J. and K.-u.L.

Funding: This research was funded by [Ministry of Science and ICT (MSIT); Ministry of Environment (ME); and Ministry of Trade, Industry and Energy (MOTIE)] grant number [NRF-2017M3D8A2085273] And The APC was funded by [NRF-2017M3D8A2085273].

Acknowledgments: This research was supported by the National Strategic Project-Carbon Upcycling of the National Research Foundation of Korea (NRF) funded by the Ministry of Science and ICT (MSIT); the Ministry of Environment (ME); and the Ministry of Trade, Industry and Energy (MOTIE), (NRF-2017M3D8A2085273).

Conflicts of Interest: The authors declare no conflict of interest.

\section{References}

1. Greenhouse Gas Inventory Research Center. National Greenhouse Gas Inventory Report of Korea; Greenhouse Gas Inventory Research Center: Seoul, Korea, 2018.

2. World Business Council for Sustainable Development. CO2 Accounting and Reporting Standard for the Cement Industry; WBCSD: Seoul, Korea, 2011.

3. IPCC. 2006 IPCC Guidelines for National Greenhouse Gas Inventories; IPCC: Geneva, Switzerland, 2006. 
4. Ministry of Environment. Instruction for the Goal Management and Operation of Greenhouse Gas Energy; Ministry of Environment: Seoul, Korea, 2016.

5. UNFCCC CDM Executive Board. ACM 0005: Increasing the Blend in Cement Production; Version 07.1.0; UNFCCC: Bonn, Germany, 2012.

6. UNFCCC CDM Executive Board. ACM 0015: Emission Reductions from Raw Material Switch in Clinker Production; Version 04.0.; UNFCCC: Bonn, Germany, 2014.

(C) 2019 by the authors. Licensee MDPI, Basel, Switzerland. This article is an open access article distributed under the terms and conditions of the Creative Commons Attribution (CC BY) license (http://creativecommons.org/licenses/by/4.0/). 